\title{
LABORATORY SIMULATIONS OF WAVE ATTENUATION BY AN EMERGENT VEGETATION OF ARTIFICIAL PHRAGMITES AUSTRALIS: AN EXPERIMENTAL STUDY OF AN OPEN-CHANNEL WAVE FLUME
}

\author{
Li YIPING ${ }^{\mathrm{a}, \mathrm{b}}$, Desmond Ofosu ANIM ${ }^{\mathrm{a}, \mathrm{b}}$, Ying WANG ${ }^{\mathrm{c}}$, Chunyang TANG ${ }^{\mathrm{b}}$, Wei DU ${ }^{\mathrm{b}}$, \\ Ni LIXIAO ${ }^{b}$, Zhongbo YUd, e, Kumud ACHARYA ${ }^{\mathrm{f}}$, Li CHEN ${ }^{\mathrm{e}, \mathrm{f}}$ \\ ${ }^{a}$ Key Laboratory of Integrated Regulation and Resource Development on Shallow Lakes, \\ Ministry of Education, Hohai University, Nanjing 210098, China \\ ${ }^{b}$ College of Environment, Hohai University, Nanjing 210098, China \\ 'Fujian Provincial Investigation, Design and Research Institute of Water Conservancy \\ and Hydropower, Fuzhou, 350001, China \\ ${ }^{d}$ Department of Geoscience, University of Nevada, Las Vegas, NV 89119, USA \\ ${ }^{e}$ State Key Laboratory of Hydrology Water Resources and Hydraulic Engineering, \\ Hohai University, Nanjing 210098, China \\ ${ }^{f}$ Division of Hydrologic Sciences, Desert Research Institute, Las Vegas, NV, 89119, USA
}

Submitted 23 Oct. 2014; accepted 25 May 2015

\begin{abstract}
This paper presents a well-controlled laboratory experimental study to evaluate wave attenuation by artificial emergent plants (Phragmites australis) under different wave conditions and plant stem densities. Results showed substantial wave damping under investigated regular and irregular wave conditions and also the different rates of wave height and within canopy wave-induced flows as they travelled through the vegetated field under all tested conditions. The wave height decreased by $6 \%-25 \%$ at the insertion of the vegetation field and towards the downstream at a mean of $0.2 \mathrm{~cm}$ and $0.32 \mathrm{~cm}$ for regular and irregular waves respectively. The significant wave height along the vegetation field ranged from $0.89-1.76 \mathrm{~cm}$ and $0.8-1.28 \mathrm{~cm}$ with time mean height of $1.38 \mathrm{~cm}$ and $1.11 \mathrm{~cm}$ respectively for regular and irregular waves. This patterns as affected by plant density and also location from the leading edge of vegetation is investigated in the study. The wave energy attenuated by plant induced friction was predicted in terms of energy dissipation factor (fe) by Nielsen's (1992) empirical model. Shear stress as a driving force of particle resuspension and the implication of the wave attenuation on near shore protection from erosion and sedimentation was discussed. The results and findings in this study will advance our understanding of wave attenuation by an emergent vegetation of Phragmites australis, in water system engineering like near shore and bank protection and restoration projects and also be employed for management purposes to reduce resuspension and erosion in shallow lakes.
\end{abstract}

Keywords: wave attenuation, aquatic emergent vegetation, open-channel, regular wave, irregular wave, shear stress.

\section{Introduction}

Coastal regions, estuaries and other natural water systems are susceptible to inundation by extreme waves and storm damping which results in flooding and events of shoreline erosion. These current situations in aquatic environment engineering and management have brought the idea of using aquatic vegetation by water resources managers in shoreline protection. Aquatic vegetation plays an important role in maintaining water level, wave and heavy storm damping and also helps maintain habitat diversity.
The presence of aquatic vegetation can reduce shear stress at the flow-sediment interface and dampen waves, thus contributing to particle deposition, reducing sediment erosion, enhancing sediment stability, and controlling sediment suspension (Koch et al. 2006; Gruber, Kemp 2010). Also, aquatic vegetation can substantially affect hydrodynamic processes at the water systems depending on fluvial morphology, vegetation spatial distribution, position and stem density (Augustin et al. 2009). Moreover, since hydrodynamics is a significant contributing factor to

Corresponding authors: Desmond Ofosu Anim; Li Chen

E-mails: desofosa@gmail.com; Li.Chen@dri.edu 
the ecosystem, the interaction between water waves and aquatic vegetation need to be quantified. Although bottom characteristics are usually a main factor in determining wave dissipation, wetlands ecosystem is particularly important as its effect on hydrodynamics is not only at the bottom but throughout the water column (Augustin et al. 2009). Hence understanding the vegetation affected hydrodynamic processes is key in understanding and maintaining the ecosystem. One important aspect is the attenuation of wave energy by aquatic vegetation (Suzuki et al. 2011). In large shallow lakes like Lake Taihu, wetlands and other natural water systems, aquatic emergent and submerged vegetation are expected to reduce bed sediments resuspension by dissipating wave energy (Houwing et al. 2002; Mendez, Losada 2004; Möller 2006).

For decades, many studies have been carried out to explore the wave and aquatic vegetation interaction focusing on vegetation induced wave attenuation (e.g. Dalrymple et al. 1984; Kobayashi et al. 1993; Mendez et al. 1999; Lovas 2000; Suzuki et al. 2011). The initial theoretical mode of wave damping was given by Dalrymple et al. (1984) who assumed plants as rigid cylinders exerting drag force on the regular waves. Kobayashi et al. (1993) proposed the idea adopting momentum and continuity equations, results of which showed exponential decay of wave height. Mendez et al. (1999) continued the work of Dalrymple et al. (1984) by considering irregular waves (Mendez, Losada, 2004). Other researchers (e.g. Dean, Bender 2006; Krauss et al. 2009) applied linear wave theory to demonstrate that the wave attenuation as a result of momentum transfer from breaking wave to the water column is minimized by two-thirds of incoming wave height as it travels through the vegetation. Augustin et al. (2009) also used linear wave theory to laboratory experiments to quantify bulk drag force exerted by vegetation. The study of aquatic vegetation attenuating wave is investigated and quantified in several laboratory studies with both natural and artificial vegetation (e.g. Dubi, Tørum 1996; Tschirky et al. 2000; Augustin et al. 2009; Cavallaro et al. 2010) and also field measurements in various different environments (Möller, Spencer 2002, Möller 2006; Quartel et al. 2007; Bradley, Houser 2009; Lövstedt, Larson 2010). In addition, modeling studies were also performed to investigate wave-vegetation interactions (Dalrymple et al. 1984; Asano et al. 1992; Mendez et al. 1999; Mendez and Losada 2004; Mullarney, Henderson 2010).

The above mentioned studies have reported changing rate of wave attenuation regarding the vegetation type and the study environment. Knutson et al. (1982) in an early study reported a decrease in wave energy in salt marsh vegetation up to $26 \%$. Mork (1996) conducted experiments on hyperborea kelp beds in the coast of Norway that showed attenuation of more than $60 \%$ of wave height. Tschirky et al. (2000) in Lake Ontario recorded a $40 \%$ reduction of wave height in emergent wetland plants. Cooper(2005) found that wave damping over salt marshes was two times higher than over mudflats. In coastal mangrove, wave damping was shown to be five times more than that due to only bed friction (Quartel et al. 2007). Fonseca and Calahan (1992) also studied the wave energy reduction by seagrass and recorded that the effect is negligible provided the plants leaf height is less than half of the water depth. However, Elwany et al. (1995) reported that wave energy is not attenuated significantly by the vegetation field which moves concurrently with the flow and also with no substantial drag effect. Large variability exists among studies of wave damping and it is very difficult to describe a general behaviour of vegetation induced wave attenuation (Mendez, Losada 2004). The complexity shows that the dynamics depend largely on the vegetation characteristics such as vegetation type, density, stiffness, spatial distribution, geometry and also the hydrodynamic conditions such as incoming wave height, wave period and water depth. The vegetation field is exposed to varying wave forcing and water flow that changes with time as plant stem characteristics changes thus making wave-vegetation interaction highly dynamic (Bradley, Houser 2009; Anderson et al. 2011).

Even though there are existing studies that describe wave-vegetation damping patterns, successful applications are still rare. Since aquatic vegetation shows large variability across the world, seeking an inferred generalized method to quantify this behaviour is difficult. The attenuation of flow within vegetation canopies is a significant part of vegetation flows which has not fully been integrated especially in prior models of dissipation by rough surfaces (vegetation) which this study will aim to explore. This study also aims to advance our understanding knowledge or description of wave-vegetation behaviour by advancing our understanding of the related processes. Also, most previous studies investigated the wave-vegetation flow into sparsely arranged vegetation with some few spaced measuring points of investigation which to the best of our knowledge do not give a detailed profile of the interactions of the in-canopy flow with individual vegetation canopy elements. We hypothesise that the dynamics affecting the dissipation of flow inside the vegetation canopies will eventually control the rate at which wave energy is attenuated which this study aims to provide a detailed wave-vegetation with various observation points. Also, as the emergent macrophytes common Reed (Phragmites australis) is becoming a predominantly species in our water ecosystem especially in eastern China (Zhang 2009; Yan et al. 2011; Li et al. 2014), its use in this study will help to understand the extent by which these species could change the habitat modifying characteristics of the ecosystem in terms of wave dissipation. The investigations about the ecosystem engineering impacts of these species is very significant from a management perspective. This is achieved 
by investigating and quantifying the wave-vegetation interaction, focusing on wave damping and transmission, and energy dissipation. The effects of plant stem density, wave conditions are discussed. Also the vertical and horizontal shear stress variations as the wave travels through the vegetation field were investigated.

In this paper, wave attenuation was investigated in well-controlled laboratory experiments with artificial emergent vegetation field under different wave conditions and vegetation stem densities. In addition, the wave energy dissipation expressed as wave energy dissipation factor and wave orbital amplitude was studied and also investigating if friction by emergent plants relates can be described by existing empirical models.

\section{Materials and method}

\subsection{Theory}

\subsubsection{Wave height and energy decay}

Generally, wave attenuation by aquatic vegetation is a result of the energy loss to the plant stems (Dalrymple et al. 1984; Mork 1996; Bradley, Houser 2009). Theories for wave energy and height decay through vegetation field have been proposed in various studies and, in the end, a general solution was proposed irrespective of the type of vegetation (Mendez et al. 1999; Möller et al. 1999; Augustin et al. 2009; Bradley, Houser 2009). The resulting general equation for wave height decay is given as:

$$
Q_{c}=\frac{H}{H_{o}},
$$

where $Q_{c}$ is the wave decay coefficient, $H$ is the incoming wave height, $H_{o}$ is the local wave height. For irregular waves, $H$ and $H_{o}$ becomes the root mean square wave height (i.e. Hrms and $\boldsymbol{H}_{\boldsymbol{o}} \boldsymbol{r m} \boldsymbol{s}$ respectively).

Dalrymple et al. (1984) proposed an algebraic equation using the linear wave theory and wave energy conservation which was later modified by Mendez and Losada (2004):

$$
\frac{H}{H_{o}}=\frac{1}{1+\beta x},
$$

where $\beta$ is parameter related to the plant and wave characteristics given as

$$
\beta=\frac{1}{3 \pi} C_{d} N d_{v} H\left[\frac{\sin ^{3} k l_{v}+3 \sinh k l_{v}}{(\sinh 2 k h+2 k h) \sinh k h}\right],
$$

where $k$ is the wave number $\left(\mathrm{m}^{-1}\right), l_{v}$ is the vegetation height, $h$ is water depth. Generally, the dissipation of wave energy depends on the characteristics of the vegetated field (configuration, density, size) and morphology of plants.

Wave energy dissipation factor above roughness elements (in the presence of vegetation), $f_{e}$ or the wave friction factors, $f_{w}$ at the bed are usually a function of the wave orbital amplitude and the hydraulic roughness, $r$ (Nielsen 1992; Soulsby 1997). Based on a large number of laboratory studies, Nielsen (1992) derived empirically the wave friction equation that reads

$$
f_{w}=\exp \left(5.5\left(\frac{r}{A}\right) 0.2-6.3\right)
$$

where $A$ is the wave orbital amplitude calculated by

$$
A=U T_{p} / 2 \pi
$$

where $T_{p}$ is peak wave period. This equation has been widely and successfully applied over rough surfaces (Manca et al. 2010; Lowe et al. 2005). In the present study, the wave energy loss as a result of the presence of vegetation was estimated by the vegetation induced friction and calculated using the commonly used dimensionless parameter $f_{e}$ modified by Manca et al. (2010). This parameter is determined from the wave energy loss in the vegetation field assuming exponential wave height decay. This friction factor was applying the formulae of Jonsson (1966) as

$$
f_{e}=\left(\frac{3}{2 \pi} \frac{\varepsilon_{f}}{\rho U_{*}}\right)
$$

where $\rho$ is the water density, $U_{\star}$ is the horizontal wave velocity above canopy, $\varepsilon_{f}$ is defined as the rate of wave energy dissipation per unit area as a result of induced friction. These two friction-based coefficients ( $f_{w}$ and $f_{e}$ ) are different in definitions, Nielsen (1992) proved that, in spite of the disparity of these two parameters shown in various experimental results, they can be assumed equal for practical applications. Manca et al. (2010) also made the similar conclusion. If the linear wave theory is applicable, $\varepsilon_{f}$ can be calculated assuming the waves are normal to the vegetation field as (Dalrymple et al. 1984)

$$
\varepsilon_{f}=\frac{\partial E C_{g}}{\partial x}
$$

where $E=\frac{1}{8} \rho g H^{2} C_{g}$ is the wave energy density, $g$ is the acceleration due to gravity, and $C_{g}=\frac{1}{2} c\left(1+\frac{2 k h}{\sin (2 k h)}\right)$, where $C_{g}$ and $c$ are group velocity and wave phase speed respectively (Infantes et al. 2012).

\subsubsection{Vegetative roughness and drag coefficient}

For the parameters mentioned above, it is shown that the mean drag coefficient, $C_{d}$, of the vegetation field is one of the most significant parameters for determining attenuation coefficients. However, it is very difficult to estimate $C_{d}$. For flows through vegetation fields, both the Darcy-Weisbach coefficient and the Manning's $n$ are used to represent the resistance coefficient. For a glass-walled wave flume like the one used in this study, the side wall 
is considered smooth and thus the sidewall resistance is negligible. The flume roughness resistance was then dominated by the vegetative roughness. The wave energy is greatly attenuated by the vegetative resistance in the wave flume. Kouwen (1996) established that vegetative roughness dominates the bed resistance instead of the surface resistance. To estimate the vegetative drag induced by the vegetal plant elements, the hydrodynamic forces $(F)$ that waves exerts on the vegetation is examined as $F=\left(F_{x}, 0\right.$, $F_{z}$ ) where $F_{z}$ normally assumed to be negligible likened to $F_{x}$ especially for shallow flow water depth. Generally, the horizontal force $\left(F_{h}\right)$ is given as $F_{h}=F_{d}+F_{i}$ (Morison et al. 1950) where $F_{d}$ is the vegetative drag force and $F_{i}$ is the inertial force. However, defining a generalized value for vegetation-induced drag is impossible since the $C_{d}$ is highly dependent on hydrodynamic and plant properties. However, $C_{d}$ is commonly regarded as a function of some non-dimensional flow parameters (Kobayashi et al. 1993; Mendez, Losada 2004), in which the most relevant one is the stem Reynolds number, Re, (Kobayashi et al. 1993; Augustin et al. 2009) which is related to $C_{d}$ as

$$
C_{d}=a+\left(\frac{\beta}{R e}\right)^{\zeta},
$$

where a, $\beta, \zeta$ are coefficients depending on the plant properties and $R e$ is defined as

$$
R e=\frac{U d}{v},
$$

where $v$ is the kinematic viscosity of water $\left(=10^{-6} \mathrm{~m}^{2} / \mathrm{s}\right.$ at $24^{\circ} \mathrm{C}$ ) and $u$ is the maximum horizontal characteristic velocity acting on the plants at the measurement point calculated from the linear wave theory as

$$
U=\frac{\pi H}{T} \frac{\cosh \left(k l_{v}\right)}{\sinh (k h)} .
$$

Kobayashi et al. (1993) calibrated $C_{d}$ values for Asano et al. (1988) experiments and plotted against the corresponding stem $R e$ and established a relationship as

\begin{tabular}{|c|c|}
\hline \multirow{2}{*}{ Property } & Value \\
\hline & Emerged \\
\hline $\begin{array}{l}\text { Plant total height } \\
\text { Approximate height }\end{array}$ & $65 \mathrm{~cm}$ \\
\hline Leaf section & $50 \mathrm{~cm}$ \\
\hline $\begin{array}{l}\text { Stem section } \\
\text { Average diameter }\end{array}$ & $15 \mathrm{~cm}$ \\
\hline Leaf section & $2.6 \mathrm{~cm}$ \\
\hline Stem section & $0.4 \mathrm{~cm}$ \\
\hline Average width & \\
\hline Leaf section & $8 \mathrm{~cm}$ \\
\hline $\begin{array}{l}\text { Average surface area } \\
\text { Leaf section }\end{array}$ & $0.025 \mathrm{~m}^{2}$ \\
\hline
\end{tabular}

$$
C_{d}=0.08+\left(\frac{2200}{R e}\right)^{2.4}
$$

Fig. 1. Image of the artificial emergent plant used for the experiment and a summary of its physical properties for Re range of $2200<R e<18000$. However, Mendez et al. (1999) through laboratory studies extended Kobayashi et al. (1993) work and derived also an empirical formula for $C_{d}$ varying with $R e$ as

$$
C_{d}=0.08+\left(\frac{2200}{R e}\right)^{2.2},
$$

for $R e$ range of $200<R e<15500$. This formula does not account for vegetation swaying (see Mendez et al. 1999) where it is assumed that the horizontal velocity of the vegetation is substantially smaller than the orbital velocity thus the vegetation can be considered to be rigid. Mendez, Losada (2004) however investigated that Keuglan Carpenter (KC) number relates appropriately the $C_{d}$ with the stem length and wave parameters expressed as

$$
K C=\frac{U_{\max } T}{d_{v}} .
$$

However, for emergent vegetation field conditions, $C_{d}$ was found to relate better with $R e$ (Augustin et al. 2009; Bradley, Houser 2009; Cavallaro et al. 2010).

\subsubsection{Bottom roughness and shear stress}

Generally, in the field and laboratory studies, Manning and Darcy-Weisbach friction factors have been successfully applied to flows through aquatic vegetation which has also been related to the wall shear stress (Galema 2009; Augustin et al. 2009). However, it has been established in literature that for a glass-walled flume, the wave energy is more attenuated by the vegetative resistance, thus vegetative roughness dominates the bed resistance (Fathi-Maghadam, Kouwen 1997). Various studies have applied different approaches in estimating the mean bottom shear stress in a flume for wave-vegetation flow interaction (Mazda et al. 1997; Cheng et al. 1999; Mendez et al. 2004; Rashid 2010; Thompson et al. 2004). Thompson et al. (2004) mentioned that the Quadratic Stress Law is suitable for estimating the mean shear stress for all kinds of fluid flow and vegetation interaction. The shear stress, $\tau$ with the Quadratic Stress Law is defined as

$$
\tau=\rho C_{d} U_{\infty}^{2}
$$

where $U_{\infty}$ is the depth averaged longitudinal flow velocity $(\mathrm{m} / \mathrm{s})$.

\subsection{Experimental setup}

The experiments were conducted in an open wave flume constructed in the Coastal, Harbor and Offshore Engineering Hydraulics Laboratory at Hohai University, China. A series of experimental runs were performed for waves propagating over an array of plastic artificial emergent plants (see Fig. 1).

The laboratory wave flume is a $30 \times 0.5 \mathrm{~m}$ glass-walled rectangular flume with a height of $1.0 \mathrm{~m}$. A piston wave 
maker controlled by a computer was used to generate waves at the upstream of the wave flume. The incoming water flow was controlled by an inlet turning valve at the upstream end and a triangular adjustable weir at the downstream end, which was also used to control the water level. At the downstream of the wave flume was a rubber wave absorber built to minimize wave reflection effects. A $7 \mathrm{~m}$ long vegetation section was constructed $15 \mathrm{~m}$ downstream from the wave maker. Artificial plastic plants were used in this study to simulate aquatic vegetation. These plants mimicked real species of common reed (Phragmites Australis). They are produced from material to generate appropriate density and flexural rigidity to approximate the real plants as possible. The plants have biomechanical and morphological resemblance to the real species they mimic and were thus suitable to be used in our studies. Fiala (1976) described the vegetative morphology and mechanical properties of Phragmites australis plant stems. This approach of using artificial plant is similar to that used by many other researchers (e.g. Nepf, Vivoni 2000; Järvelä 2005; Chen et al. 2011; Li et al. 2014) who investigated scale models of vegetation and have found it is important to use simplified form plants to the real vegetation. Each individual artificial plant has a total height of $0.65 \mathrm{~m}(0.5 \mathrm{~m}$ stem section and $0.15 \mathrm{~m}$ leaf section) with a mean plant width of $0.08 \mathrm{~m}$. It has an average diameter of $0.026 \mathrm{~m}$ and $0.04 \mathrm{~m}$ at the leaf and stem section respectively. The plant were built on a $7 \mathrm{~m} \times 0.5 \mathrm{~m} \times 0.01 \mathrm{~m}$ $(\mathrm{L} \times \mathrm{W} \times \mathrm{H})$ board with holes and placed on the flume bed to develop the vegetation section. The schematic view of the experimental setup is shown in Figure 2. Figure 3 shows an image of the flume with the planted vegetation. The water depth in the flume was kept approximately at $0.5 \mathrm{~m}$ for all the experimental runs.

\subsection{Instrumentation and experimental runs conditions}

To investigate the effect of plant stem density and varied wave conditions on attenuation under emergent conditions, twelve scenarios were examined. Table 1 shows the conditions of these experimental runs. In addition, four vegetation densities $\left(\mathrm{stems} / \mathrm{m}^{2}\right)$ ranging from 30 to $90 \mathrm{stems} / \mathrm{m}^{2}$ which represent a typical aquatic configuration in most rivers in the eastern china (CVEC 1980; Ma et al. 2008; Zhang 2009) and six wave conditions for both regular $(R)$ and irregular (IR) waves were selected to represent different wave heights and periods (see Table 1). Each experiment was assigned a specific code name in this paper based on the plant stem density and wave condition (see Table 1). For example, WIE90 indicates experimental run 1 under $90 \mathrm{stems} / \mathrm{m}^{2}$ plant density and a regular wave of $3 \mathrm{~cm}$ wave height $(H)$ and 1.0 s wave period $(T)$. Also, W4E90 indicated experimental run 4 under $90 \mathrm{stems} / \mathrm{m}^{2}$ plant density and an irregular wave of $H=4.24 \mathrm{~cm}$ and
$T=1.11$ s. Code names with W1, W2 and W3 represent regular waves and the rest for irregular waves. The wave transformation along the flume was monitored by 10 wave gauges which measured the free surface oscillations time series (wave height and period). These were distributed at one meter interval beginning $1 \mathrm{~m}$ upstream of the vegetation section. Figure 4 shows the locations (Locations 1 to 10) of the wave gauges along the vegetation section in the flume. Locations 1 and 10 were located at upstream and downstream outside the vegetation section respectively whereas Locations 2 to 9 were located within the vegetation section.

Instantaneous velocity measurements were taken by a 3D macro acoustic Doppler velocimeter (ADV) (SonTek, San Diego, CA, USA) at a sampling frequency of $20 \mathrm{~Hz}$ at various positions (Positions 1 to 5 ) along the vertical direction with a $30 \mathrm{~s}$ sampling time. A total of 600 data points were collected at each position. A mean velocity value at each measuring point was obtained by using WinADV post-processing software. This velocity data were to

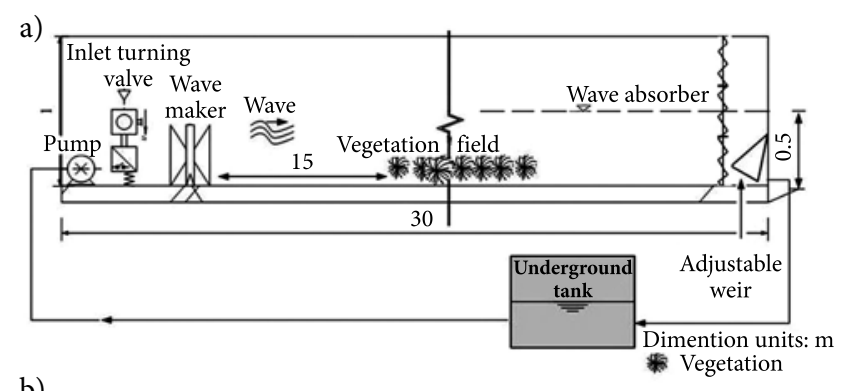

b)

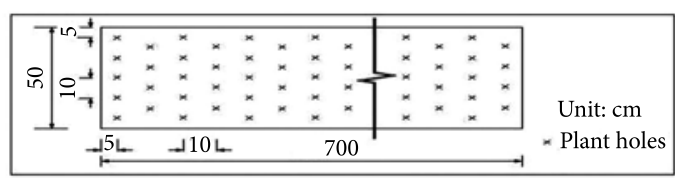

Fig. 2. a) Schematic view of the experimental flume setup; b) Plan view of the boards in which the artificial plants were arrange to create the vegetation field
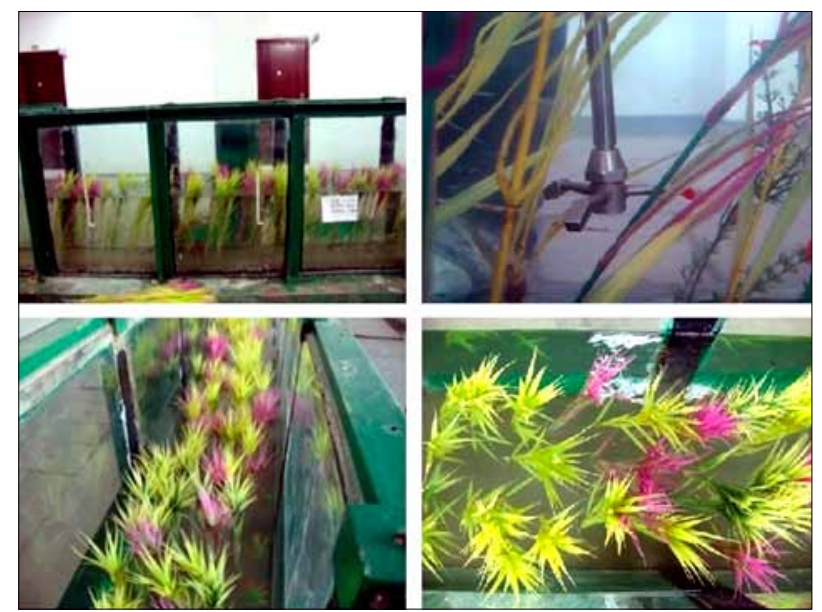

Fig. 3. Image of the flume with the planted vegetation 
be used later in estimating the vertical and longitudinal shear stresses in the flume. Figure 4 shows the ADV measuring positions. Positions 1 and 5 are located outside the vegetated regions whereas Positions 2, 3 and 4 are within the vegetated region. Velocity measurements were taken at fourteen points along the vertical direction starting from $5 \mathrm{~cm}$ above the flume bed. Measurements were taken at $2.5 \mathrm{~cm}$ and $5 \mathrm{~cm}$ intervals spaces near the bed and towards the surface respectively (i.e. $2.5 \mathrm{~cm}$ increments from 5 to $20 \mathrm{~cm}$, and then $5 \mathrm{~cm}$ increments from 20 to $40 \mathrm{~cm}$ ). Thus, there were a total of 14 measuring points vertically.

\subsection{Wave data analysis}

For the various experimental runs, the data were analyzed to quantify the wave decay by the vegetation field. The wave attenuation patterns as well as the estimation of the drag properties are of interest. For each of the 10 wave gauge points along the vegetation field, the root meansquare height $\left(H_{r m s}\right)$ and the mean wave period were determined from each water oscillation time series. This was

Table 1. The twelve experimental runs tested and their conditions. $\mathrm{R}$ and IR represent regular and irregular wave respectively

\begin{tabular}{cccccc}
\hline $\begin{array}{c}\text { Expt. } \\
\text { run }\end{array}$ & $\begin{array}{c}\text { Vegetation } \\
\text { density } \\
\left(\mathrm{stem} / \mathrm{m}^{2}\right)\end{array}$ & $\begin{array}{c}\text { Wave } \\
\text { type }\end{array}$ & $T(\mathrm{~s})$ & $H(\mathrm{~cm})$ & $\begin{array}{c}\text { Code } \\
\text { name }\end{array}$ \\
\hline 1 & 90 & $\mathrm{R}$ & 1 & 3 & W1E90 \\
2 & 90 & $\mathrm{R}$ & 1.2 & 3 & W2E90 \\
3 & 90 & $\mathrm{R}$ & 1 & 4.5 & W3E90 \\
4 & 90 & IR & 1.11 & 4.24 & W4E90 \\
5 & 90 & IR & 1.33 & 4.24 & W5E90 \\
6 & 90 & IR & 1.11 & 6.36 & W6E90 \\
7 & 70 & $\mathrm{R}$ & 1 & 4.5 & W3E70 \\
8 & 70 & IR & 1.11 & 6.36 & W6E70 \\
9 & 50 & $\mathrm{R}$ & 1 & 4.5 & W3E50 \\
10 & 50 & IR & 1.11 & 6.36 & W6E50 \\
11 & 30 & $\mathrm{R}$ & 1 & 4.5 & W3E30 \\
12 & 30 & IR & 1.11 & 6.36 & W6E30 \\
\hline
\end{tabular}

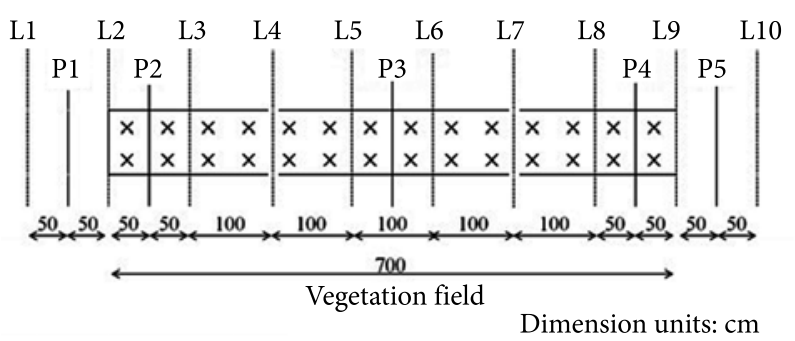

Fig. 4. Measuring points within the flume for both ADV and wave gauges. Wave gauge locations are shown by L1 to L10 and ADV velocity measuring points are shown by $\mathrm{P} 1$ to $\mathrm{P} 5$ where $\mathrm{P}$ and $\mathrm{L}$ represents Positions and Locations respectively. obtained by employing a wave-by-wave analysis using post processing wave software which applies a zero-crossing method (Mizuguchi 1982; Augustin et al. 2009; Zhang et al. 2011) to calculate the significant wave height $\left(H_{s}\right)$ and the peak wave period $(T)$. The zero-crossing method represents average water surface fluctuations most accurately (Möller et al. 1999). Wave heights were obtained from the wave spectral for each wave gauge points for irregular waves. For irregular waves, $H_{s}$ were converted to $H_{r m s}$ using the relation $\left(H_{r m s}=H_{s} / 1.416\right)$. The wave height decay coefficient $\left(Q_{c}\right)$ was estimated from equation 1 .

\section{Results and discussions}

\subsection{Wave heights and energy attenuation}

The experimental data indicated that the wave height greatly decayed whiles the wave travelled through the vegetation field (see Fig. 5). For emergent conditions, the whole velocity profile is obstructed by the plant stems. Figure 5 shows the trend of wave height decay coefficient changing with distance through the vegetation section for all runs.

Generally, for emergent conditions, irrespective of the plant stem density or wave condition, the wave height decreased when the wave propagated through the vegetation section. The greater part of wave height attenuated over the vegetation field mostly occurred along the first few meters of the vegetation field (from Locations 1 to 3) (see Fig. 5) which was observed for both regular and irregular waves runs. This was similar to the findings observed by previous researchers (Kobayashi et al. 1993; Mendez, Losada 2004; Augustin et al. 2009). This obvious great effect is due to the fact that when wave travelling through emergent vegetation, the drag effects from the plant are distributed throughout the water depth where the velocity profile is obstructed. The decay however decreased with distance along the vegetation field.

Also in Fig. 5, the theoretical wave decay coefficient as calculated by Equation 2 was plotted against the experimental results of $Q_{c}$. It was observed that the theoretical equation provides a good fit to the experimental data. For all experimental runs, the experimental wave height data follows the proposed theoretical equation for wave height decay by Dalrymple et al. (1984) and Mendez and Losada (2004) which describe exponential wave height decays through vegetation zones.

The wave height was observed to decrease beyond gauge measuring point 3 at Location 3. Generally, the $H_{s}$ decrease by a mean $0.2 \mathrm{~cm}$ for regular waves experimental runs and $0.32 \mathrm{~cm}$ for irregular waves runs over the vegetation filed between Locations 2 to 9 . The $H_{s}$ decreased by $\sim 25 \%$ between Location 2 and 5 at a distance of $3 \mathrm{~m}$ and then averagely $\sim 6 \%$ from Locations 5 to 9 . The $H_{s}$ turns to increase at Location 2 when it first contacts the vegetation field and also from Locations 9 to 10 after leaving the vegetation field. The significant wave height along the vegetation 
field ranged from $0.89-1.76 \mathrm{~cm}$ with a time mean $H_{s}$ of $1.38 \mathrm{~cm}$ for regular waves and $0.8-1.28 \mathrm{~cm}$ with a time averaged $H_{s}$ of $1.11 \mathrm{~cm}$ for irregular waves. This study suggest that for an incident regular wave of $3 \mathrm{~cm}<H<4.5 \mathrm{~cm}$ and $1 \mathrm{~s}<T<1.2 \mathrm{~s}$ moving over a constant depth of $0.5 \mathrm{~m}$, the percentage wave height attenuation was of values of $13.6 \%$ decrease for the first $3 \mathrm{~m}$ within the vegetation section at position 5 and $6.4 \%$ decrease for the next $3 \mathrm{~m}$ till the end of the vegetation section and increase slightly just after at position 10. Similar trend occurred for an incident irregular wave of $4.24 \mathrm{~cm}<H<6.36 \mathrm{~cm}$ and $1.11 \mathrm{~s}<T<1.33 \mathrm{~s}$ with an attenuation of $7.6 \%$ decrease for first $3 \mathrm{~m}$ and a further mean 2.4\% decrease. Qualitatively, the results in this present study correspond to that of Mendez and Losada (2004) and Augustin et al. (2009), even though the magnitudes of wave height decay are not the same. Hence, such deviation could be as a result of different condition pertained to the depth of water, different stem densities and plants characteristics. For most experimental runs, the wave height increased at the edge of the vegetation field before decreasing for both regular and irregular waves. This observation could be as due to the frictional dissipation in some of the experimental runs. This could also be explained as a result of the local wave interaction caused by the immediate impediment and change in bottom configuration experienced by the waves. This behavior was also reported in regular waves results by Bradley and Houser (2009) and Stratigaki et al. (2011).
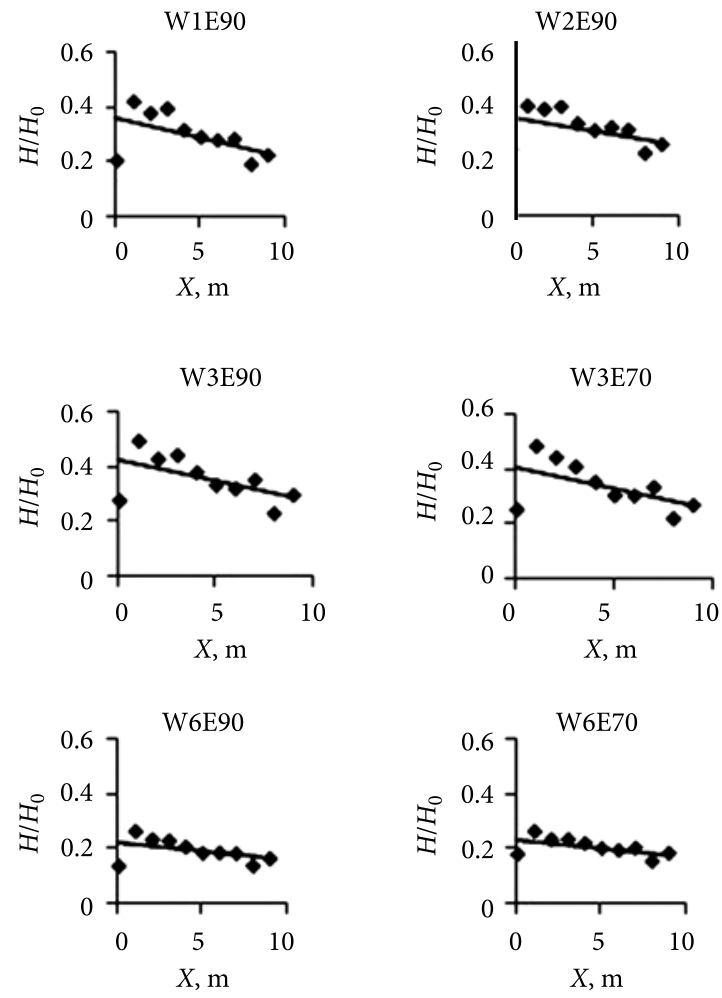

experiments
The experimental runs with the larger canopy density showed the greatest wave height decay. The higher stem densities resulted in greater attenuation irrespective of the wave condition but were most prominent in the regular wave experiment runs. The results also exhibit a rapid increase in wave decay with large incident wave height for regular wave experimental runs and less wave attenuation with increasing wave height for irregular wave experimental runs. For the same plant stem density, this trend also existed. The wave height decay reduction with the accumulation of the water depth and wave length ratio could be explained as the results of the very less penetration of the wave propagation within the water column as it travels along the vegetation section which results in a less wave induced flow and plants interactions.

The wave height decay $\left(Q_{c}\right)$ which occur exponentially ranged from 0.2 to 0.58 with a mean coefficient of 0.3 for regular wave runs whereas that of irregular waves runs ranged from 0.12 to 0.26 with a mean coefficient of 0.16 . The fluctuation of the $Q_{c}$ turns to depend on the $R e$ where the characteristic velocity was the velocity related with the peak spectral wave. The highest $Q_{c}$ was observe for the largest $R e$ observed $(25000<R e<45000)$ and the smallest $Q_{c}$ observed for the lowest $R e$ observed $(R e<20000)$. Figure 6 shows the rate of wave energy attenuation as it passes through the vegetation field. The result shows a significant wave energy reduction as a result
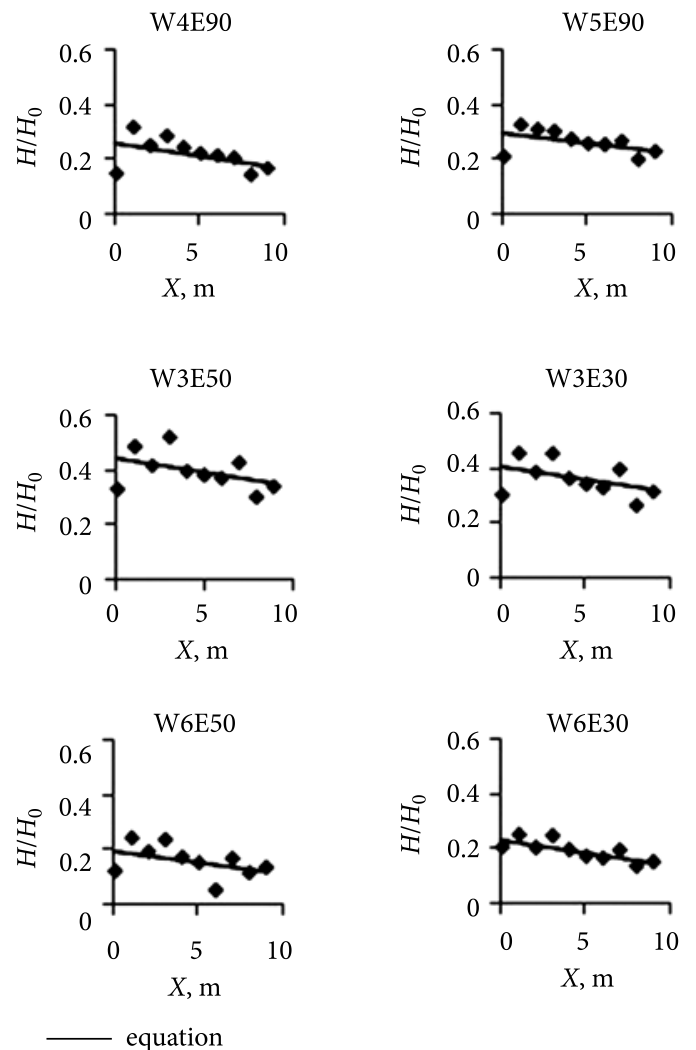

Fig. 5. Experimental and numerical results of wave height decay coefficient $\left(Q_{C=} H_{o} / H\right)$ variation over the emergent artificial vegetation field for all the experimental runs tested. 
of the interaction between the plants and wave induced flows. The wave energy dissipation was found to be maximum at the first two transects within the vegetation. For the same plant stem density (see Fig. 6a), the rate of dissipation trend seems not to change after travelling through the first $2 \mathrm{~m}$ of the vegetation section. The rate of dissipation for a high incident wave period and wave height was minimum and decrease gradually as the wave travels through the vegetation section towards a near-zero value. Similarly, for short wave period and small incident wave height, the rate of dissipation was high (with a mean $10 \%$ dissipation rate every $1 \mathrm{~m}$ ) and decreased rapidly as the wave travels. However, a higher amount of wave energy was dissipated about $3 \mathrm{~m}$ within vegetation field. From Figure $6 c$, it was could be said that irregular wave energy was largely dissipated compared to regular wave experimental runs. This corresponded to the drag coefficient which was higher for irregular wave run cases than the regular wave run cases. Considering the vegetation density, it was observed that the small plant stem density induced higher rate of energy dissipation especially at the edge of the vegetation field which decreased as the wave travels

a)

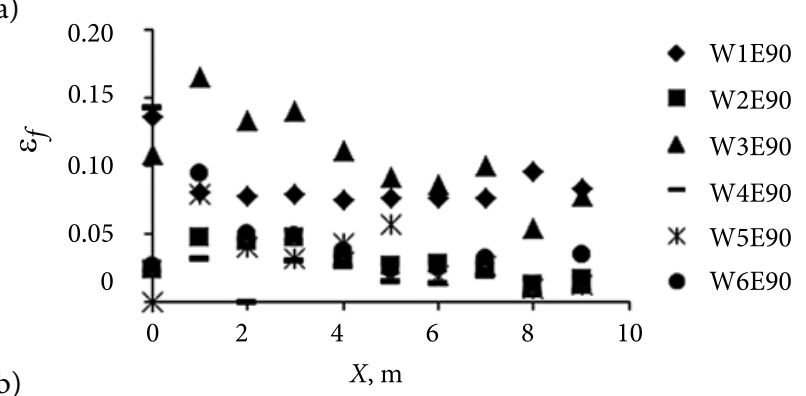

b)

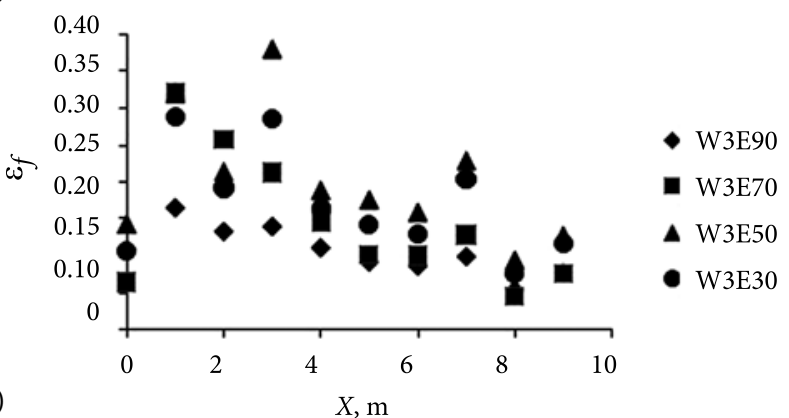

c)

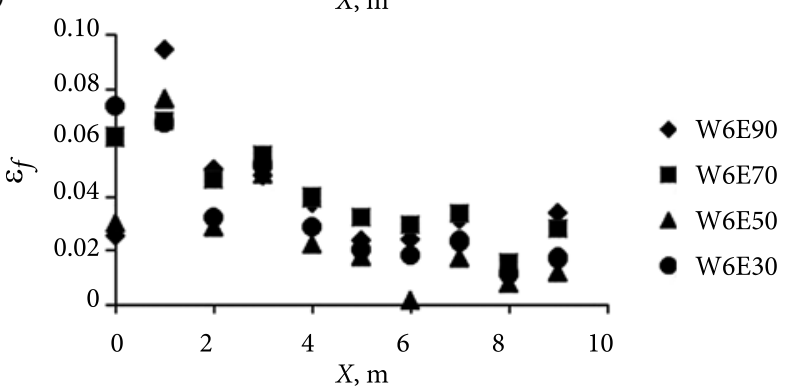

Fig. 6 . The rate of wave energy attenuation variation over the emergent artificial vegetation field for all the experimental runs tested: a) for same plant stem density; b) regular wave experimental runs; c) irregular wave experimental runs through the vegetation section. However, the rate of energy dissipation caused by the higher plants stem density seems to small and turns to be stable with little change as the wave travels through the vegetation section.

\subsection{Wave energy dissipation factor}

In this study, the wave energy attenuation as influenced by the friction induced by the presence of the vegetation field was estimated in terms of $f_{e}$. This has often been expressed as a function of the wave orbital amplitude (Manca et al. 2012). The $f_{e}$ decayed with increasing $A$. For each experimental runs, the corresponding wave energy dissipation factor $\left(f_{e}\right)$ were computed using Equation (5) for regular wave $\left(f_{e}^{r}\right)$ and irregular wave runs $\left(f_{e}^{i r}\right)$. Figure 7 shows wave energy dissipation factors $\left(f_{e}\right)$ plotted against the wave orbital amplitude $(A)$. There were not much difference of $f_{e}$ values for low and high plant stem density. For low plant stem density, the $f_{e}$ values were lower (0.007-0.014) and 0.006-0.09 for high plant stem density. The friction produced by vegetation field under irregular wave was higher than regular wave.

Augustin et al. (2009) modeled $f_{e}$ and had values between 0.05-0.19 for low density artificial Salt-marsh under emergent conditions and Möller et al. (1999) obtained values between $0.07-0.28$ in a natural Salt-marsh for plant stem density between $150 \mathrm{gm}^{-2}$ and $800 \mathrm{gm}^{-2}$. These $f_{e}$ values were in the higher part of range of that found in this study. This could be due to the difference in vegetation characteristics. The ability for emergent vegetation to attenuate wave energy is known to change with vegetation characteristics (stiffness, morphology) and wave conditions (Bouma et al. 2005; Koch et al. 2009; Paul, Amos 2011; Manca et al. 2012). Thus, to have meaningful comparisons of results becomes quite difficult. Generally, this study shows a clear decrease in $f_{e}$ with an increasing $A$ over the emergent vegetation field (see Fig. 7). This could be explained that the friction induced by the vegetation field is not the same across all wave amplitudes. The decreasing trend demonstrates the dependency of the $f_{e}$ on the wave periods. This is however fairly scattered for irregular wave runs which is most likely to be due to $f_{e}$ dependence on other local flow conditions (i.e. $R e$ ). The $f_{e}$ expectedly changed as a function of $A$ in agreement to the Nielsen (1992) empirical model (see Eq. (4)). With this, a strong correlation coefficient $(0.95, n=11, P<0.05)$ was produced for a hydraulic roughness $(r=0.03)$, where $n$ is the sample size for each experimental run and $P$ is the probability value. Higher peak wave period and incident wave height experience gradual decrease dissipation rate than short wave period and small incident wave height which experience high dissipation and decreases rapidly as the wave travels especially within the vegetated region. 
a)
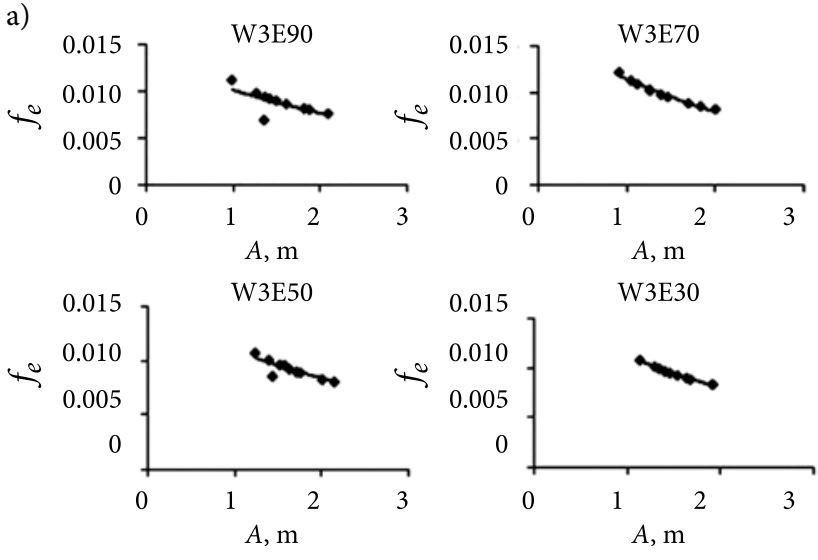

$-f_{e}-$ Nielsen
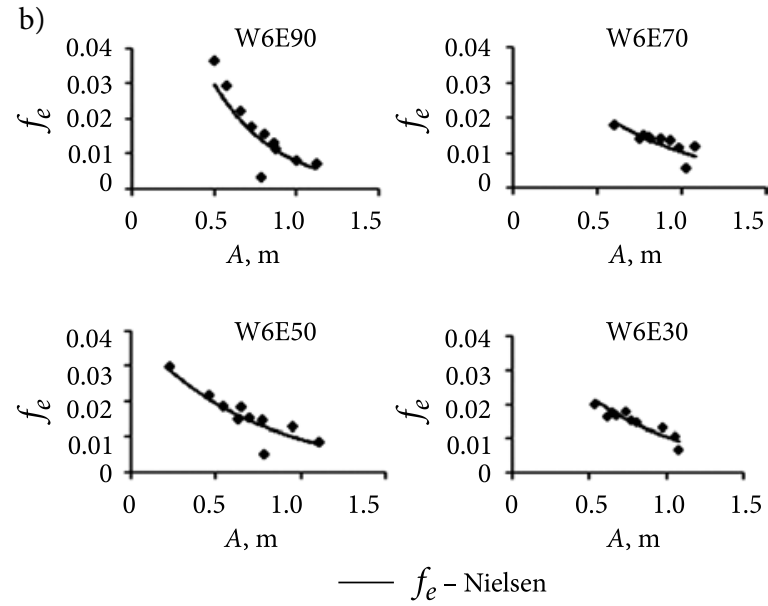

c)

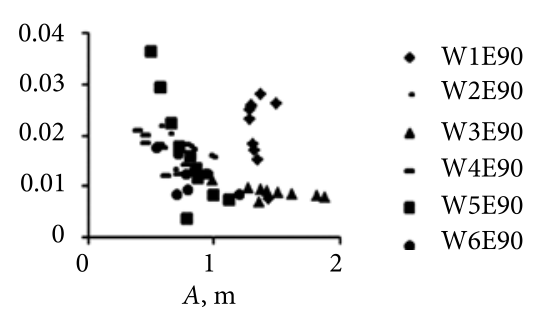

\subsection{Vegetation roughness and drag coefficient}

Using Equation 2 and the observed wave energy decay, the plant stem drag coefficient was calculated for each experimental runs. It is important to note that the representative effective drag coefficient was computed under the presumption of rigid vegetation as the reflection measured from the plants was less than $8 \%$ and therefore neglected. The $C_{d}$ changes considerably similar to the wave decay coefficient and dissipation which ranging from 0.05 to 0.8 with a mean $C_{d}$ of 0.12 for regular waves conditions and from 0.1 to 1.5 with a mean $C_{d}$ of 0.6 for irregular waves. Fig. 8 shows a plot of the $C_{d}$ against $R e$ and $K C$ following Kobayashi et al. (1993) and Mendez et al. (1999). It shows that the drag coefficient decreased as the waves decay under emergent conditions which resulted in reduction of the attenuation rate. It was observed that the $C_{d}$ decreased with increasing $R e$. For very large $R e$, the $C_{d}$ was to an order of 0.01 . For the irregular waves experimental runs, the $C_{d}$ produced a more scattering phenomena which resulted in a weak correlation coefficients. However, the correlation between $C_{d}$ and Re for regular wave experimental runs yielded an improvement in the correlation coefficient results with less scatter. Similar observation was made for the correlation coefficient between $C_{d}$ and $K C$. This indicated a weak dependency between $C_{d}$ and wave period. However, the correlation here yielded is very weak. This confirms the claims made by various researchers that $C_{d}$ depends directs on the Re (e.g. Mendez and Losada, 2004; Augustin et al. 2009; Bradley and Houser 2009). Considering relatively the impact of the plant stem density on $C_{d}$, it is generally observed that the lower stem density
(30 and $50 \mathrm{stems} / \mathrm{m}^{2}$ ) produced lower stem drag coefficient compared to the higher stem density (70 and 90 stems $/ \mathrm{m}^{2}$ ). Table 2 gives the mean $C_{d}$ for each run. From Fig. $8 \mathrm{a}$, it is seen that for the same stem plant density, the irregular wave run cases yield higher $C_{d}$ than the regular wave run cases. This corresponds to the observation in the wave height attenuation (see Fig. 5) for irregular wave experimental runs where the larger attenuation was experienced through the vegetation field. a)
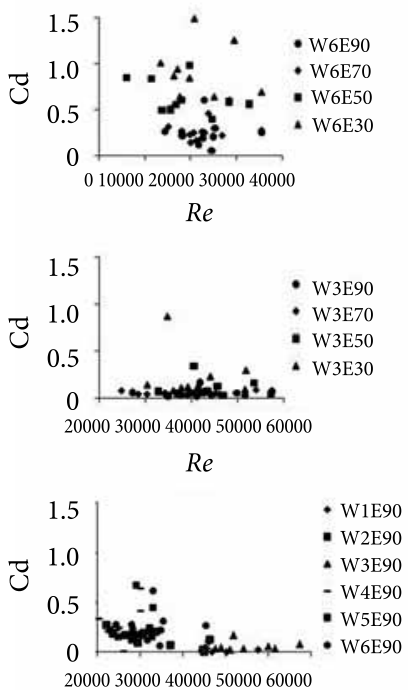

$R e$ b)
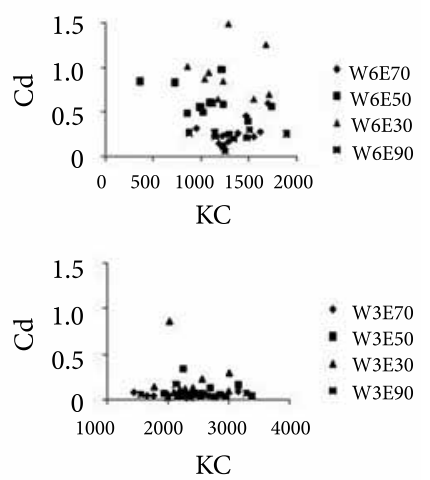

$\mathrm{KC}$

$\mathrm{KC}$

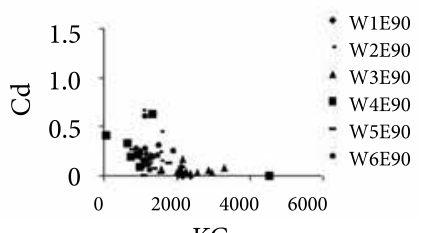

Fig. 8. Relationship between the plant stem drag coefficient $\left(C_{d}\right)$ and the Reynolds number $(R e)(\mathrm{a})$ and KeuglanCarpenter (KC) (b) for regular (W3) and irregular (W6) and the same plant stem density experimental runs calculated locally at each measurement location. 
Table 2. The vegetation drag coefficient values for the twelve experimental runs tested. $\mathrm{R}$ and IR represent regular and irregular wave respectively

\begin{tabular}{cccccc}
\hline $\begin{array}{c}\text { Code } \\
\text { name }\end{array}$ & $\begin{array}{c}\text { Wave } \\
\text { type }\end{array}$ & $C_{d}$ & $\begin{array}{c}\text { Code } \\
\text { name }\end{array}$ & $\begin{array}{c}\text { Wave } \\
\text { type }\end{array}$ & $C_{d}$ \\
\hline W1E90 & $\mathrm{R}$ & 0.205 & W3E70 & $\mathrm{R}$ & 0.061 \\
W2E90 & $\mathrm{R}$ & 0.245 & W6E70 & IR & 0.295 \\
W3E90 & $\mathrm{R}$ & 0.058 & W3E50 & $\mathrm{R}$ & 0.104 \\
W4E90 & IR & 0.202 & W6E50 & IR & 0.238 \\
W5E90 & IR & 0.149 & W3E30 & $\mathrm{R}$ & 0.220 \\
W6E90 & IR & 0.253 & W6E30 & IR & 0.301 \\
\hline
\end{tabular}

\subsection{Effect of plant density}

Figure 9 shows the effect of plant stem density $(N)$ on the wave height attenuation for a constant wave height and wave period (see Fig. 9 a, b). The experimental data shows that the stem density greatly impacts the wave attenuation under emergent conditions. This effect is obvious and mostly within the first two wavelengths of wave propagation within the vegetation field. It was found that immediately after the entering the vegetation section, a small local wave height increase occurred particularly for higher $N$ which could be to be as a result of the sudden presence of the vegetation section. It was also found that the wave height increases at the last two wavelengths within the vegetation section towards the end with increasing $N$. This may be due to the fact that as wave induced flow is more and more impeded by the plants as it travels, part of wave

a)

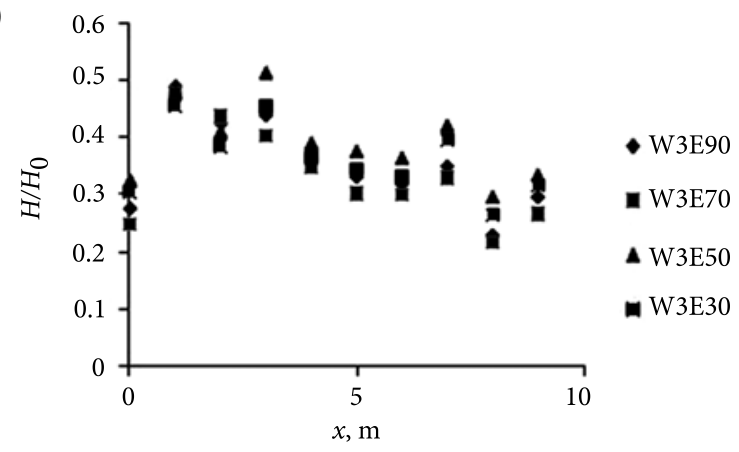

b)

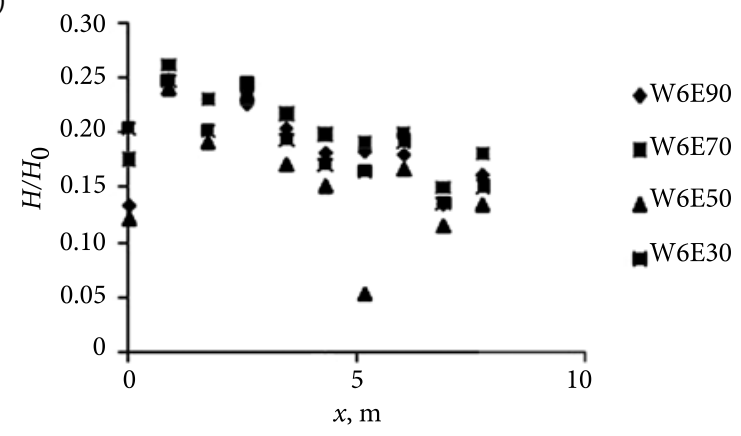

Fig. 9. Effect of plant stem density $\left(N\right.$, stem $/ \mathrm{m}^{2}$ on the wave height decay coefficient $\left(Q C=H_{0} / H\right)$ variation over the emergent artificial vegetation field: a) eregular wave experimental runs; b) irregular wave experimental runs energy is reflected and the wave height increases. The influence of the stem density on the wave attenuation was also characterized in this study as a function of the effective drag coefficient representing the average drag force per unit area across the wave propagation. This was obtained from theories in the literature as proposed by Dalrymple et al. (1984) and improved by Mendez and Losada (2004) related to coefficients which depend on the plant properties like the stem density and often related to the $R e$. Generally, in some cases the lower $N$ experimental runs for both wave types resulted in higher $C_{d}$ values compare to higher $N$ runs. This resulted in higher wave decay coefficients which suggest that the analytical decayed wave height as given in Equation (2) will be higher. The higher $C_{d}$ by lower $N$ in these cases was explained by Augustin et al. (2009) as a result of an artifact of sheltering among individual plant stem such that the effective velocity acting on an individual plant at higher plant stem densities is reasonably low compared to that of an unsheltered stem. This could also be explained by the lower Re. For the same wave conditions, wave height decay depending on the $N$ appears to be increased with increasing plant density.

\subsection{Effect of wave period}

Figure 10 shows the effect of wave period on the wave attenuation in the vegetation section. Here, $Q_{c}$ is plotted for the same plant stem density $\left(90 \mathrm{stems} / \mathrm{m}^{2}\right.$ ) and different wave conditions. Increases of the wave period and wave length resulted in a higher reduction of wave height as wave travelled along the vegetation zone, even though the difference observed between the tested wave periods was not very substantial for both the regular (W1E90 and W2E90) and irregular (W4E90 and W5E90). The high incident wave height are normally attenuated by the vegetation section with maximum $12 \%$ wave height attenuation observed even for $T=1$ and $1.11 \mathrm{~s}$ and dense plant stem. The wave decay rate rises with the wave period for the small values of $T$ to a point and reduces gradually for the large values of $T$ to an almost asymptotic

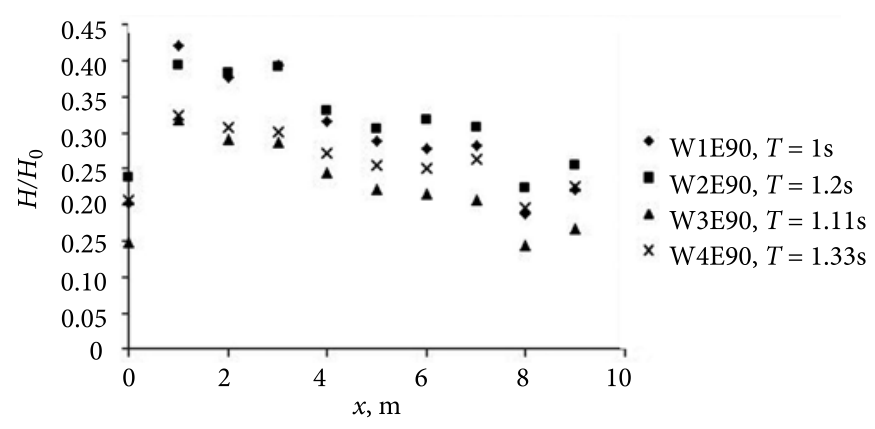

Fig. 10. Effect of wave period $(T)$ on the wave height decay coefficient $\left(Q C=H_{0} / H\right)$ variation over the emergent artificial vegetation field 
value as it travels through the vegetation field. The experimental wave decay coefficients changes more widely for short peak wave periods and nearly converge for longer $T$. It could be said considering the various peak wave periods, the theoretical wave decay coefficient is nearly independent of the peak periods regardless of the slight decrease. This is in agreement with Huang et al. (2011) investigations which reported that the wave transmission coefficients mostly depend on the vegetation density and incident wave height.

\subsection{Shear stress distribution under wave-vegetation interaction}

Figure 11 shows profiles of the longitudinal and vertical distribution of shear stress for the different plant stem density and wave conditions. The results show that the vertical distribution could be divided into two parts: (a) the lower layer $(z \leq 15 \mathrm{~cm})$, from the bottom bed which is also the stem section of the plant and (b) the upper layer which is from $z \geq 15 \mathrm{~cm}$ to the canopy of the plant towards the free water surface. This shows that the shear stress profile is complex and keeps changing within the flow depth. The shear stress the lower layer $(z=2-10 \mathrm{~cm})$ was nearly zero for most flow conditions. In general, the shear stress within the vegetated region (Position 2 to 4 ) was maximum at $z=0-2 \mathrm{~cm}$ and decreased gradually at the lower layer $(2 \mathrm{~cm} \leq z \leq 10 \mathrm{~cm})$ and then experienced a rapid increase at $z=10-15 \mathrm{~cm}$. It then decreased gradually towards the free water surface especially at Positions 3 and 4 within the vegetated region. For regular wave runs, maximum shear occurred at the lower layer and decreased towards free surface. Also, outside the vegetated region,
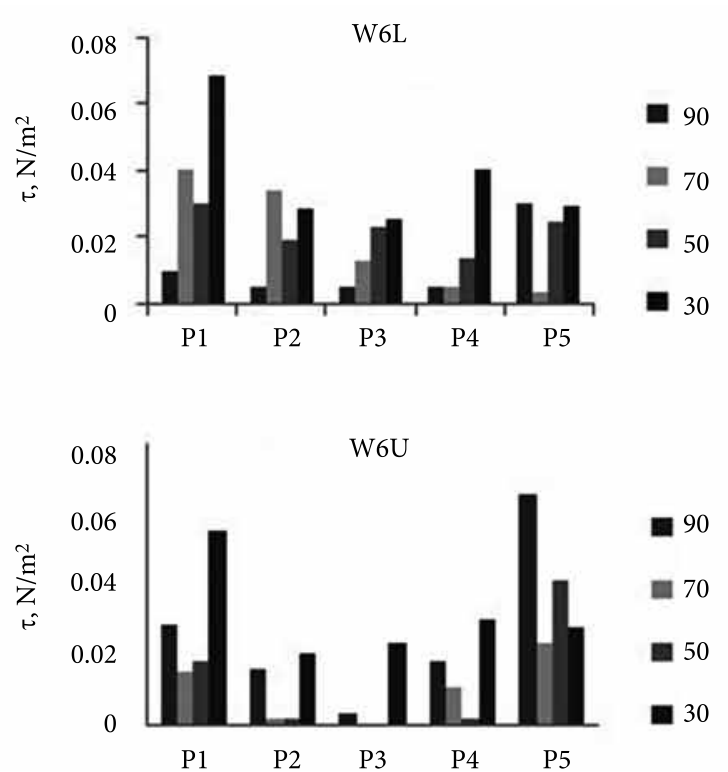

shear stress was higher which explains that emergent plant stem greatly reduced the shear. Within the vegetated region, shear stress increased slightly at $z=25-30 \mathrm{~cm}$ at Positions 3 and 4. Longitudinally, in the direction of the flow, it is observed that $\tau$ decreased as the wave travelled within the vegetated field especially at the lower layer where there is a lot of impediment for emergent conditions.

a)

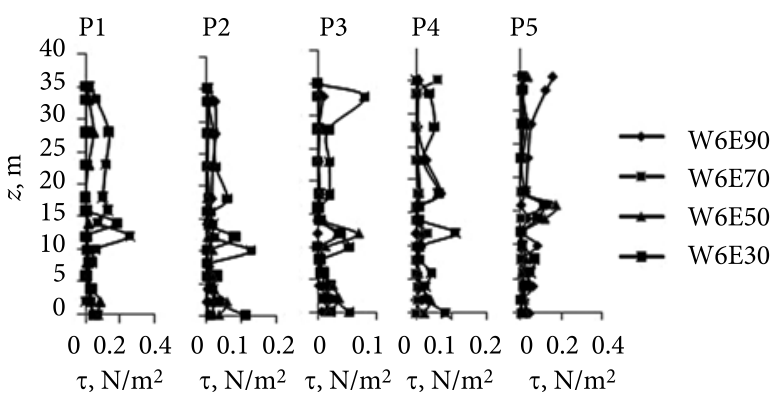

b)

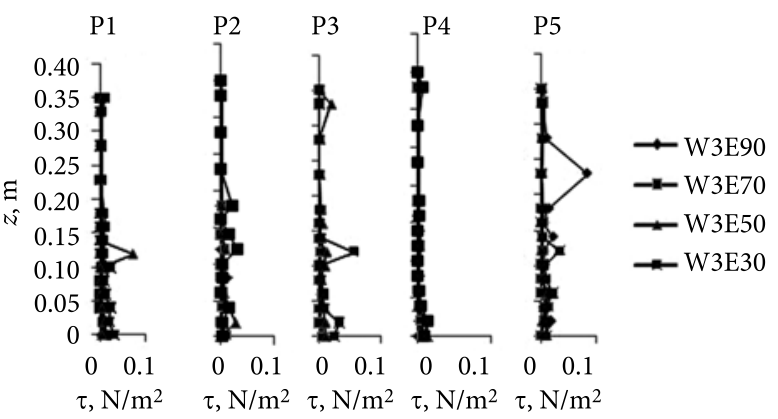

Fig. 11. The vertical and longitudinal distribution profiles of shear stress over the vegetation field. (a) Irregular wave experimental runs and (b) Regular wave experimental runs. $z$ represents the flow depth; $\mathrm{P} 1, \mathrm{P} 2, \mathrm{P} 3, \mathrm{P} 4$, and $\mathrm{P} 5$ represent Position 1 to Position 5 as described in Figure 4

Fig. 12. The longitudinal profiles of shear stress induced by different plant stem densities under different wave conditions. W3 and W6 represent regular and irregular waves runs respectively. $\mathrm{L}$ and $\mathrm{U}$ represent the lower $(z \leq 0.15 \mathrm{~m})$ and upper $(z \geq 0.15 \mathrm{~m})$ layer within the flow depth respectively. P1 to P5 are the various positions within the vegetation field (Fig. 4) 
To investigate the impact of plant stem density inducing shear stress reduction, a mean $\tau$ was estimated for the lower and upper layer respectively. Figure 12 shows the impact of plant stem density on $\tau$ as the waves travelled through the vegetation field at the various positions (1 to 5) both at the lower and upper layer. It is observed that, averagely, the $\tau$ was maximum at the upper layer for all plant stem density compared to the lower layer. The $\tau$ was smallest for the highest plant stem density at the upper layer especially within the vegetated region from Positions 2 to 4 . Maximum $\tau$ reduction both at the upper and lower layer were with the lowest plant stem density $\left(30 \mathrm{stem} / \mathrm{m}^{2}\right)$ followed by $50 \mathrm{stem} / \mathrm{m}^{2}$. The shear stress was nearly linear distributed in the longitudinal direction in the downstream of vegetated region. This shows that $\tau$ variation turned to be stable within the water depth from the middle (Position 3) of the vegetated region to downstream. By comparing the near bed shear stress downstream outside of the vegetation area with that upstream before the vegetation area, we found that the near bed shear stress reduction rate by vegetation field was larger with smaller vegetation density but this trend diminishes in the upper layer towards the free water surface. This correspond with the rate of wave energy dissipation where the lower plant stem density seems to cause more energy loss as the wave travels through the vegetation field (Fig. 6). It was found that the effect of plant stem density in inducing $\tau$ decrease as the wave travels through the vegetation field compared to outside the vegetated zones (Positions 1 and 5).

\subsection{Implication of wave attenuation on nearshore protection and sedimentation dynamics}

Aquatic emergent vegetation has the ability to protect near shore and river banks from erosion and also to mitigate riverbed sediment resuspension (Kothyari et al. 2009; Anderson et al. 2009; Harvey et al. 2011). Research has proven that aquatic plants generally acting as transition zones between dry land and open water could serve as buffer and reduce storm surge and travelling waves significantly before they reach near shore or banks. Also, it is known that aquatic plants can reduce shear stress especially close to the bottom bed near sediment interface by damping wave activity effect hence contributing to reducing the rate of particle resuspension and sediment erosion reduction and also enhance sediment stability (Larsen et al. 2009; Gruber, Kemp 2010). In this study, it has been established that aquatic emergent plants has the ability to create rough surface impacting the travelling waves which resulted in substantial wave energy decay especially for small-orbital amplitude waves. The wave damping rate increases under emergent conditions where wave height decreased significantly as it travels through the vegetation field either for a small or long values of peak wave period. Enough work was performed by the plant stems resulting in reduction of energy and thus smaller wave heights affecting the waveinduce flows significantly especially for long wavelengths. These findings suggest that emergent plants are capable to protect the water bed and also provide protection for near shore and banks from erosion. The wave decay is a function of plants characteristics such as density and also wave conditions such as incident wave height and period. In this study it was established that shear stress which is a driving force behind sediment resuspension and erosion (Hamilton, Mitchell 1997) within the flow depth is substantially reduced under emergent conditions as the waveinduced flow is reduced. It was observed that the near bed shear reduction rate by emergent plants was high even with smaller plant stem density. The small plant stem density will be able to produce locally sheltered conditions as they were effective to minimize wave-induce flow at the bed thereby reducing shear stresses. The shear stress near the lower layer was nearly reduced zero for most flow conditions. This was in agreement with James et al. (2004) who reported that the bottom shear stress was very small even at high wind speeds (i.e. $>30 \mathrm{~km} / \mathrm{h}$ ). It is reported by Dieter (1990) that in shallow marsh lakes, sediment resuspension rate in areas protected by emergent plants was only one-third of that in the open water. It was also found that, the wave-induced flow reduction hence wave height and energy decay and also shear stress reduction rate decreases as the wave travels through the vegetation field. This indicates that vegetation field size should be considered especially in restoration projects when assessing the capacity of the vegetation to stabilize the bottom bed and also protect nearshore and bank erosion. Manca et al. (2012) mentioned that fragmentation of the vegetation field to a series of aquatic plants will decrease its potential to minimize wave energy and stabilize the bed.

\section{Conclusions}

The present experimental study has focused on wave attenuation and transformation around an artificial emergent vegetation field under different conditions in an openchannel wave flume. The experimental results indicate that artificial emergent plants (Phragmitis australis) are effective in attenuating wave energy under both regular and irregular waves. The wave height measured along the vegetated region indicated wave damping along the emergent vegetated plants. An increases in plant density in the experimental runs tested induced high wave damping, heightened wave-induced flow deceleration. This trend was confirmed under both regular and irregular waves. The wave height decay had the same pattern for all the experimental run conditions and seemingly depends on the incident wave height and the plant stem density where greater decay occurred along the first few meters from 
the leading edge of the vegetation field and decrease as it travels through the vegetated field. The experimental wave decay coefficient changes more widely for short wave peak periods and nearly converge for longer wave periods whereas theoretical wave decay coefficient is nearly independent of the peak periods regardless of the slight decrease. A decrease of the wave period reduces the wave height along the vegetation for higher plant stem density. The wave energy attenuation as influenced by the friction induced by the emergent plants could be predicted in terms of energy dissipation factor $\left(f_{e}\right)$ by an empirical formula [Nielsen (1992) model]. There was a clear decrease in $f_{e}$ with an increasing A over the emergent vegetation field. However the energy decay was not uniform for all A. Within the vegetated region, the emergent plants are efficient at reducing wave-induced flows near the bed thereby reducing local momentum exchange towards the bottom bed which is good for reducing local sediment transport and resuspension. The near bed shear reduction rate by emergent plants was high even with smaller plant stem density. The results from the shear stress distribution analysis under wave-vegetation interaction shows this trend which indicates that they will be able to promote greater sediment stabilization compared to un-vegetated bed. The shear results show that conditions at the upper layer at the edge of canopy are more turbulent and wave-induced flows are less reduced than within the lower layer at the stem section where more uniform and stable hydrodynamics conditions exists. These findings would prove useful to help further our understanding of wave attenuation by emergent aquatic plants and in water system engineering such as near shore and bank protection and in restoration projects.

\section{Acknowledgements}

The research was supported by Chinese National Science Foundation (51579071, 51379061, 41323001, 51539003), and Jiangsu Province National Science Foundation (BK20131370), and National Science Funds for Creative Research Groups of China (No. 51421006); the program of Dual Innovative Talents Plan and Innovative Research Team in Jiangsu Province, the Special Fund of State Key Laboratory of Hydrology-Water Resources and Hydraulic Engineering and the Fundamental Research Funds for the Central Universities The authors are indebted to the anonymous reviewers for their constructive comments and thorough reviews of the paper.

\section{References}

Anderson, M. E.; Smith, J. M.; Mckay, S. K. 2011. Wave dissipation by vegetation, ERDC/CHL Coastal and Hydraulics Engineering Technical Note 1(82): 1-22.
Asano, T.; Deguchi, H.; Kobayashi, N. 1992. Interactions between water waves and vegetation, in Proceedings of the 23rd International Conference on Coastal Engineering ASCE, 4-9 October 1992, Venice, Italy, 2710-2723.

Augustin, L. N.; Irish, J. L.; Lynett, P. 2009. Laboratory and numerical studies of wave damping by emergent and nearemergent wetland vegetation, Coastal Engineering 56: 332340. http://dx.doi.org/10.1016/j.coastaleng.2008.09.004

Bradley, K.; Houser, C. 2009. Relative velocity of seagrass blades: implications for wave attenuation in low-energy environments, Journal of Geo-physical Research 114: 1-14. http://dx.doi.org/10.1029/2007JF000951

Bouma, T. J.; De Vries, M. B.; Low, E.; Peralta, G., et al. 2005. Trade-offs related to ecosystem engineering: a case study on stiffness of emerging macrophytes, Ecology 86(8): 2187-2199. http://dx.doi.org/10.1890/04-1588

Cavallaro, L.; Re, C. L.; Paratore, G.; Viviano, A.; Foti, E. 2010. Response of Posidonia oceanica to wave motion in shallowwaters: preliminary experimental results, in Proceedings of the 32nd International Conference on Coastal Engineering, Coastal Engineering Research Council, 30 June - 5 July 2010, Shanghai, China, 1-10.

Cheng, R. T.; Ling, C.; Gartner, J. W. 1999. Estimates of bottom roughness length and bottom shear stress in San Francisco Bay, California, Journal of Geophysical Research 104: 77157728. http://dx.doi.org/10.1029/1998JC900126

Chen, S. C.; Kuo, Y. M.; Li, Y. H. 2011. Flow characteristics within different configurations of submerged flexible vegetation, Journal of Hydrology 398: 124-134. http://dx.doi.org/10.1016/j.jhydrol.2010.12.018

Cooper, N. J. 2005. Wave dissipation across intertidal surfaces in the Wash Tidal inlet, Eastern England, Journal of Coastal Research 21(1): 28-40. http://dx.doi.org/10.2112/01002.1

Chinese Vegetation Editional Council (CVEC). 1980. Vegetation in China. Beijing: Science Press (in Chinese).

Dalrymple, R. A.; Kirby, J. T.; Hwang, P. A. 1984. Wave diffraction due to areas of energy dissipation, Journal of Waterway, Port, Coastal, and Ocean Engineering 110(1): 67-79. http://dx.doi.org/10.1061/(ASCE)0733-950X(1984)110:1(67)

Dean, R. G.; Bender, C. J. 2006. Static wave setup with emphasis on damping effects by vegetation and bottom friction, Coastal Engineering 53: 149-156.

http://dx.doi.org/10.1016/j.coastaleng.2005.10.005

Dieter, C. D. 1990. The importance of emergent vegetation in reducing sediment resuspension in wetlands, Journal of Freshwater Ecology 5(4): 467-473. http://dx.doi.org/10.1080/02705060.1990.9665263

Dubi, A.; Tørum, A. 1996. Wave energy dissipation in kelp vegetation, in Proceedings of the 25th International Conference on Coastal Engineering, ASCE, 2-6 September 1996, Orlando, USA, 2626-2639.

Elwany, M. H. S.; O’Reilly, W. C.; Guza, R. T.; Flick, R. E. 1995. Effects of Southern California kelp beds on waves, Journal of Waterway Port Coastal Ocean Engineering 121(2): 143-150. http://dx.doi.org/10.1061/(ASCE)0733950X(1995)121:2(143)

Fathi-Maghadam, M.; Kouwen, N. 1997. Nonrigid, nonsubmerged, vegetative roughness on floodplains, Journal of Hydraulic Engineering 123(1): 51-57.

http://dx.doi.org/10.1061/(ASCE)0733-9429(1997)123:1(51) 
Fiala, K. 1976. Underground organs of Phragmites communis, their growth, biomass and net production, Folia Geobotanica et Phytotaxonomica 11(3): 225-259. http://dx.doi.org/ 10.1007/BF02909471

Fonseca, M. S.; Cahalan, J. A. 1992. A preliminary evaluation of wave attenuation by four species of seagrass, Estuarine, Coastal, and Shelf Science 35(6): 565-576. http://dx.doi.org/10.1016/S0272-7714(05)80039-3

Galema, A. 2009. Evaluation of vegetation resistance descriptors for flood management: Master Thesis. University of Twente, Enschede, Netherlands.

Gruber, R. K.; Kemp, W. M. 2010. Feedback effects in a coastal canopy-forming submerged plant bed, Limnology and Oceanography 55(6): 2285-2298.

http://dx.doi.org/10.4319/lo.2010.55.6.2285

Hamilton, D. P.; Mitchell, S. F. 1997. Wave-induced shear stresses, plant nutrients and chlorophyll in seven shallow lakes, Freshwater Biology 38: 159-168.

http://dx.doi.org/10.1046/j.1365-2427.1997.00202.x

Harvey, J. W.; Noe, G. B.; Larsen, L. G., et al. 2011. Field flume reveals aquatic vegetation's role in sediment and particulate phosphorus transport in a shallow aquatic ecosystem, Geomorphology 126(3-4): 297-313.

http://dx.doi.org/10.1016/j.geomorph.2010.03.028

Houwing, E. J.; Tanczos, I. C.; Kroon, A.; de Vries, M. B. 2002. Interaction of submerged vegetation, hydrodynamics and turbidity; analysis of field and laboratory studies, Proceedings in Marine Science 5: 441-453.

http://dx.doi.org/10.1016/S1568-2692(02)80032-8

Huang, Z.; Yao, Y.; Sim, S. Y.; Yao, Y. 2011. Interaction of solitary waves with emergent, rigid vegetation, Ocean Engineering 38: 1080-1088. http://dx.doi.org/10.1016/j.oceaneng.2011.03.003

Infantes, E.; Orfila, A.; Simarro, G., et al. 2012. Effect of a seagrass (Posidonia oceanica) meadow on wave propagation, Marine Ecology Progress Series 456: 63-72.

http://dx.doi.org/10.3354/meps09754

James, W. F.; Barko, J. W.; Butler, M. G. 2004. Shear stress and sediment resuspension in relation to submersed macrophyte biomass, Hydrobiologia 515: 181-191.

http://dx.doi.org/10.1023/B:HYDR.0000027329.67391.c6

Järvelä, J. 2005. Effect of submerged flexible vegetation on flow structure and resistance, Journal of Hydrology 307: 233-241. http://dx.doi.org/10.1016/j.jhydrol.2004.10.013

Jonsson, I. G. 1966. Wave boundary layers and friction factors, in Proceedings of 10th International Conference on Coastal Engineering, September 1966, Tokyo, Japan, 127-148.

Knutson, P. L.; Bronchu, R. A.; Seelig, W. N. 1982. Wave damping in Spartina alternifora marshes, Wetlands 2(1): 87-104. http://dx.doi.org/10.1007/BF03160548

Kobayashi, N.; Raichle, A. W.; Asano, T. 1993. Wave attenuation by vegetation, Journal of Waterway, Port, Coastal, and Ocean Engineering 119(1): 30-48.

http://dx.doi.org/10.1061/(ASCE)0733-950X(1993)119:1(30)

Koch, E. W.; Barbier, E. B.; Silliman, B. R., et al. 2009. Non-linearity in ecosystem services: temporal and spatial variability in coastal protection, Frontiers in Ecology and the Environment 7: 29-37. http://dx.doi.org/10.1890/080126

Koch, E. W.; Sanford, L. P.; Chen, S-N.; Shafer, D. J.; Smith, J. M. 2006. Waves in seagrass systems: review and technical recommendations. United States Army Corps of Engineers.
Kothyari, U. C.; Hashimoto, H.; Hayashi, K. 2009. Effect of tall vegetation on sediment transport by channel flows, Journal of Hydraulic Research 47: 700-710. http://dx.doi.org/10.3826/jhr.2009.3317

Kouwen, N.; Fathi-Moghadam, M. 1996. Friction factors for vegetation, in The Proceedings of 2nd International Symposium on Habitat Hydraulics, Ecohydraulics, A251-A267, June 1996, IAHR/INRS-EAU, Quebec, Canada.

Krauss, K. W.; Doyle, T. W.; Doyle, T. J., et al. 2009. Water level observations in mangrove swamps during two hurricanes in Florida, Wetlands 29(1): 142-249. http://dx.doi.org/10.1672/07-232.1

Larsen, L. G.; Harvey, J. W.; Crimaldi, J. P. 2009. Predicting bed shear stress and its role in sediment dynamics and restoration potential of the Everglades and other vegetated flow systems, Ecological Engineering 35(12): 1773-1785. http://dx.doi.org/10.1016/j.ecoleng.2009.09.002

Li, Y.; Anim, D. O.; Ying, W.; Chunyang, T.; Wei, D.; Yu, Z.; Kumud, A. 2014. An open channel flume study of flow characteristics through combined layer of submerged and emerged flexible vegetation, Ecohydrology 7: 633-647. http://dx.doi.org/10.1002/eco.1384

Lovas, S. M. 2000. Hydro-physical condition in kelp forests and effect on wave damping and dune erosion: a case study on Laminaria Hyperborea: PhD Thesis, The Norwegian University of Science and Technology, Trondheim, Norway.

Lövstedt, C. B.; Larson, M. 2010. Wave damping in reed: Field measurements and mathematical modelling, Journal of $\mathrm{Hy}$ draulic Engineering 136(4): 222-233. http://dx.doi.org/10.1061/(ASCE)HY.1943-7900.0000167

Lowe, R. J.; Falter, J. L.; Bandet, M. D.; Pawlak, G.; Atkinson, M. J.; Monismith, S. G.; Koseff, J. R. 2005. Spectral wave dissipation over a barrier reef, Journal of Geophysical Research: Oceans 110(C04001): 1-16.

Ma, R.; Duan, H.; Gu, X.; Zhang, S. 2008. Detecting aquatic vegetation changes in Taihu Lake, China using multi-temporal satellite imagery, Sensors 8(6): 3988-4005. http://dx.doi.org/10.3390/s8063988

Manca, E.; Caceres, I.; Alsina, J. M., et al. 2012. Wave energy and wave-induced flow reduction by full-scale model Posidonia oceanica seagrass, Continental Shelf Research 50-51: 100-116. http://dx.doi.org/10.1016/j.csr.2012.10.008

Manca, E.; Stratigaki, V.; Prinos, P. 2010. Large scale experiments on spectral wave propagation over Posidonia oceanica seagrass, in Proceedings of 6th International Symposium on Environmental Hydraulics, 23-25 June 2010, Athens, Greece, 463-468. http://dx.doi.org/10.1201/b10553-74

Mazda, Y.; Magi, M.; Kogo, M.; Hong, P. N. 1997. Mangroves a coastal protection from waves in the Tong King delta, Vietnam, Mangroves and Salt Marshes 1: 127-135. http://dx.doi.org/10.1023/A:1009928003700

Mendez, F. J.; Losada, I. J. 2004. An empirical model to estimate the propagation of random breaking and nonbreaking waves over vegetation fields, Coastal Engineering 53: 103-118. http://dx.doi.org/10.1016/j.coastaleng.2003.11.003

Mendez, F. J.; Losada, I. J., Losada, M. A. 1999. Hydrodynamics induced by wind waves in a vegetation field, Journal of Geophysical Research 104(C8): 18383-18396. http://dx.doi.org/10.1029/1999JC900119

Mizuguchi, M. 1982. Individual wave analysis of irregular wave deformation in the nearshore zone, in Proceedings of 18th 
Coastal Engineering Conference, 14-19 November 1982, Cape Town, South Africa, 485-504.

Möller, I. 2006. Quantifying saltmarsh vegetation and its effect on wave dissipation. Results from the UK East Coast saltmarsh, Estuarine, Coastal, and Shelf Science 69: 337-351. http://dx.doi.org/10.1016/j.ecss.2006.05.003

Möller, I.; Spencer, T. 2002. Wave dissipation over macrotidal saltmarshes: Effects of marsh edge typology and vegetation change, Journal of Coastal Research S136: 506-521.

Möller, I.; Spencer, T.; French, J. R.; Leggett, D. J.; Dixon, M. 1999. Wave transformation over salt marshes: a field and numerical modeling study from North Norfolk, England, Estuarine, Coastal, and Shelf Science 49(3): 411-426. http://dx.doi.org/10.1006/ecss.1999.0509

Morison, J. R.; O’Brien, M. P.; Johnson, J. W.; Schaaf, S. A. 1950. The force exerted by surface waves on piles, Journal of Petroleum Technology 2(5): 149-154. http://dx.doi.org/10.2118/950149-G

Mork, M. 1996. The effect of kelp in wave damping, Sarsia 80: 323-327.

Mullarney, J. C.; Henderson, S. M. 2010. Wave-forced motion of submerged single-stem vegetation, Journal of Geophysical Research 115(C12). http://dx.doi.org/10.1029/2010JC006448

Harvey, J. W.; Noe, G. B.; Larsen, L. G.; Nowacki, D. J.; McPhillips, L. E. 2011. Field flume reveals aquatic vegetation's role in sediment and particulate phosphorus transport in a shallow aquatic ecosystem, Geomorphology 126: 297-313. http://dx.doi.org/10.1016/j.geomorph.2010.03.028

Nepf, H. M.; Vivoni, E. R. 2000. Flow structure in depth-limited vegetated flow, Journal of Geophysical Research 105: 547-557. http://dx.doi.org/10.1029/2000JC900145

Nielsen, P. 1992. Coastal bottom boundary layers and sediment transport, in Advanced Series on Ocean Engineering 4. Singapore: World Science.

Paul, M.; Amos, C. L. 2011. Spatial and seasonal variation in wave attenuation over Zostera noltii, Journal of Geophysical Research 116 (C08019): 1-16.

Quartel, S.; Kroon, A.; Augustinus, P. G. E. F.; Van San-ten, P.; Tri, N. H. 2007. Wave attenuation in coastal mangroves in the Red River Delta, Vietnam, Journal of Asian Earth Sciences 29(4): 576-584. http://dx.doi.org/10.1016/j.jseaes.2006.05.008

Rashid, S. M. H. 2010. Effectiveness of widely used critical velocity and bed shear stress equations for different types of sediment beds: Master's Thesis, Washington State University [online], [cited 20 May 2014]. Available from Internet: http://www. dissertations.wsu.edu/Thesis/Fall2010/s_rashid_113010.pdf

Soulsby, R. L. 1997. Dynamics of marine sands: a manual for practical application. London: Thomas Telford.

Stratigaki, V.; Manca, E.; Prinos, P., et al. 2011. Large-scale experiments on wave propagation over Posidonia oceanica, Journal of Hydraulic Research 49: 31-43. http://dx.doi.org/10.1080/00221686.2011.583388

Suzuki, T.; Zijlema, M.; Burger, B.; Meijer, M.C.; Narayan, S. 2011. Wave dissipation by vegetation with layer schematization in SWAN, Coastal Engineering 59: 64-71. http://dx.doi.org/10.1016/j.coastaleng.2011.07.006

Thompson, C. E. L.; Amos, C. L.; Lecouturier, M.; Jones, T. E. R. 2004. Flow deceleration as a method of determining drag coefficient over roughened flat beds, Journal of Geophysical Research 109: 1-12. http://dx.doi.org/10.1029/2001JC001262

Suzuki, T.; Zijlema, M.; Burger, B.; Meijer, M. C.; Narayan, S. 2011. Wave dissipation by vegetation with layer schematization in SWAN, Coastal Engineering 59: 64-71.

Tschirky, P.; Hall, K.; Turcke, D. 2000. Wave attenuation by emergent wetland vegetation, in Proceedings of the 27th International Conference on Coastal Engineering, ASCE, 16-21 July 2000, Sydney, Australia, 865-877.

Yan, S.; Yu, H.; Zhang, L.; Xu, J.; Wang, Z. 2011. Water quantity and pollutant fluxes of inflow and outflow rivers of Lake Taihu, 2009, Journal of Lake Science 23(6): 855-862 (in Chinese). http://dx.doi.org/10.18307/2011.0605

Zhang, S. R. 2009. Common wetland plants in China. Beijing: Science Press.

Zhang, Y.; Xu, Y.; Xia, J. 2011. Analysis of dispersion and attenuation of surface waves in poroelastic media in the exploration-seismic frequency band, Geophysical Journal International 187: 871-888. http://dx.doi.org/10.1111/j.1365-246X.2011.05168.x

Li YIPING is an Associate professor at the College of Environment, Hohai University, China and the director of the Department of Environmental Engineering. He received his $\mathrm{PhD}$ in Environmental engineering from Hohai University, China in 2006. His research involves lake ecosystems and numerical models. He is especially interested in the whole process of hydrologic cycle and contaminant transport among land, surface water and groundwater and water environment protection. His present research is focused on the integrated watershed model linking hydrodynamic, water quality, optical, marine science and ecological models. He has published more than 50 peer-reviewed scientific articles in high impact journals and presented his work at international conferences.

Desmond Ofosu ANIM is a current postgraduate researcher (Environmental Engineering) at the College of Environment, Hohai University, China. Research interests include water environment protection, water pollution control, ecohydrology, storm water management. He is an author and co-author to over 15 scientific articles in high impact peer-reviewed journals and also presented his work at international conferences.

Ying WANG is a researcher at the Fujian Provincial Investigation, Design and Research Institute of Water Conservancy and Hydropower, China. She holds a Master's degree in Environmental engineering, Hohai University. Research interests include water resources management, environmental pollution control. She is an author and co-author to over 10 scientific articles in high impact peer-reviewed journals. 
Chunyang TANG is a current PhD fellow (Environmental Science) at the College of Environment, Hohai University, China. Research interests include water environment protection, water pollution control, lake management, water resources hydrodynamic modeling. She is an author and co-author to over 20 scientific articles in high impact peer-reviewed journals. Tang has presented her works at various international conferences.

Wei DU is a current PhD fellow (Environmental Engineering) at the College of Environment, Hohai University, China. Research interests include water resources protection, water pollution control, river and lake hydrodynamic modeling. She is an author and co-author to over 7 scientific articles in high impact peer-reviewed journals.

Ni LIXIAO is currently an Associate professor at the College of Environment, Hohai University, China. She received her Ph.D degree from Nanjing University, China in 2004. Her research interests involve wastewater treatment and restoration of the aquatic ecosystems. She is especially interested in the algae control and wastewater treatment with constructed wetland. She is an author and co-author to over 30 scientific articles in high impact peer-reviewed journals.

Zhongbo YU, Professor, is currently the Dean of the College of Hydrology and Water Resources, Hohai University, China and also a professor of Hydrogeology and Hydrology at the Department of Geoscience, University of Nevada, Las Vegas. Zhongbo Yu has conducted research on development and application of distributed hydrologic models for hydrology and climate studies; characterization and evaluation of surface water, groundwater, and groundwater contamination; multiphase and multicomponent transport in saturated and unsaturated porous media; image processing and computing visualization. His current studies include the distributed modeling of hydrologic response to atmospheric forcing in the Susquehanna river basin, field monitoring and numerical modeling of dynamic hydrologic processes in small watersheds, and interactions among atmosphere, land surface, and groundwater. He is an author and co-author to over 200 scientific articles in high impact peer-reviewed journals and also serve as both editor and reviewer to various scientific journals. He has given presentation and lecture at various international conferences and workshops.

Kumud ACHARYA is a research professor of ecological engineering at the Division of Hydrologic Sciences, Desert Research Institute, Las Vegas. He hold PhD degree in Biology and Environmental Science, Saitama University, Saitama, Japan. His research interests include water quality, environmental restoration, invasive species, hydrology, eco-hydrology, nutrient cycling, wastewater treatment systems, groundwater management, and ecological modeling. His specific studies involve observational and experimental studies at various scales, including laboratory cultures (zooplankton, algal chemostats), short-term field experiments and sustained whole-ecosystem manipulations. He is an author and co-author to over 150 scientific articles in high impact peer-reviewed journals and also serve as both editor and reviewer to various scientific journals, such as Journal of Hydrologic Engineering, Journal of the American Water Resources Association and so on. He has given presentation and lecture at various international conferences and workshops.

Li CHEN is an Associate Research Professor at the Division of Hydrologic Sciences, Desert Research Institute, Las Vegas. He hold $\mathrm{PhD}$ degree in Fluid Mechanics, Chinese Academy of. Research interests include water movement and waterinitiated material transport in surface and shallow ground environment that include dynamics and numerical modeling of rainfall-infiltration-runoff process; sediment transport monitoring and modeling in natural water body; hydrodynamic and contaminant transport modeling in near surface water system; soil erosion dynamics and geomorphologic evolution. $\mathrm{He}$ is an author and co-author to over 60 scientific articles in high impact peer-reviewed journals. 